
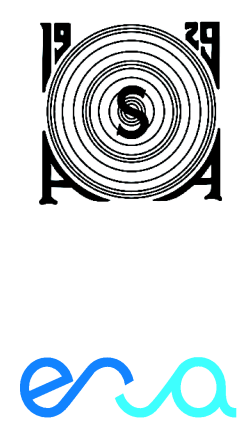

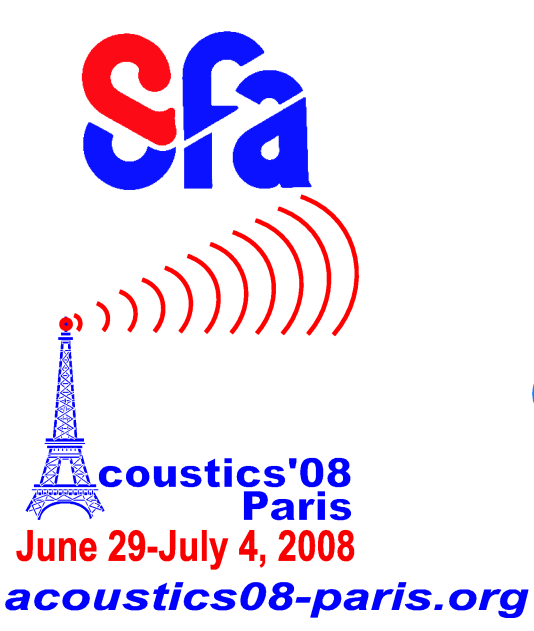

www.acoustics08-paris.org
EAA

euronoise

\title{
Response to wind turbine noise in the Netherlands
}

E. Pedersen ${ }^{\mathrm{a}}$, J. Bouma ${ }^{\mathrm{b}}$, R. Bakker ${ }^{\mathrm{b}}$ and F. Van Den Berg ${ }^{\mathrm{c}}$

${ }^{a}$ Occupational and Environmental Medicine, Göteborg University, PO Box 100, SE-405 30 Göteborg, Sweden

${ }^{\mathrm{b}}$ Northern Centre for Healthcare Research, University Medical Centre Groningen, PO Box 30001, 9700 RB Groningen, Netherlands

${ }^{\mathrm{c}}$ University of Groningen - Science \& Society Group, Nijenborgh 4, 9747AG Groningen,

Netherlands

eja.pedersen@set.hh.se 
A cross-sectional study with the objective to explore the impact of wind turbine noise on people living in the vicinity of wind farms was carried out in the Netherlands in 2007. A postal questionnaire assessing response to environmental exposures in the living area, including wind turbine noise, was answered by 725 respondents (response rate: 37\%). Immission levels of wind turbine noise outside the dwelling of each respondent were calculated in accordance with ISO-9613. The risk for being annoyed by wind turbine noise outdoors increased with increasing sound levels $\left(\mathrm{r}_{\mathrm{s}}=0.501, \mathrm{n}=708, \mathrm{p}<0.001\right)$. The risk for annoyance was decreased for respondents who could not see wind turbines from their dwelling and for respondents who benefited economically from the turbines. No statistically significant correlations between immission levels of wind turbine noise and health or well-being were found. However, noise annoyance due to wind turbine noise was associated with stress symptoms, psychological distress and lowered sleep quality.

\section{Introduction}

Wind turbines generate electricity with no emission of green house gases and are hence beneficial for the environment. Wind power is also favoured by the public on a general level [1]. However, people living in areas selected as suitable for future wind farms have expressed concerns about the impact of wind turbines, especially that of the noise [2]. In the process to develop recommendations and regulation for this new type of power plants, governmental and local authorities have also taken an interest in the environmental impact of the turbines on the surroundings, including nearby residences. The first published attempts to model a dose-response relationship between levels of wind turbine sound and the risk for annoyance with the sound were based on the results from two Swedish studies [3, 4]. The proportion of respondents annoyed by wind turbine noise was indicated to be larger than those of other community noise sources such as transportation and industry at comparable levels. At immission levels 37.5$40.0 \mathrm{~dB}(\mathrm{~A})$, calculated as sound pressure levels at the dwelling of the resident from wind turbines in a downwind condition of $8 \mathrm{~m} / \mathrm{s}, 6-28 \%$ of the respondents in the studies stated that they were rather or very annoyed by the noise outdoors. At levels above $40.0 \mathrm{~dB}(\mathrm{~A})$ the proportions of rather or very annoyed respondents were $15-44 \%$. Even though the immission levels were not transformed into the commonly used LDEN-values, and therefore not directly comparatively to other studies estimating annoyance from transport [5] and industry [6], the relatively high proportions of annoyed at such low levels are notable. Visual aspects such at the visibility of the wind turbines and the individual attitude towards the impact of the turbine on the landscape scenery were found to moderate the response to the sound, but only in some types of landscapes [7]. More data, collected in different settings, are therefore needed before a more generalized dose-response relationship for wind turbine noise could be modelled.

The study WINDFARMperception was carried out in the Netherlands in 2007. The objectives were to assess the prevalence of annoyance from noise and visual exposure in relation to sound pressure levels and apparent size among people living in the vicinity of wind farms, to identify factors interacting with annoyance, and to explore possible health effects. In this paper, the response to wind turbine noise and major moderating factors are reported. Some findings of associations between wind turbine noise and health are also described, but possible adverse health effects will be discussed in a forthcoming paper.

\section{Method}

The relationship between sound pressure levels from wind turbines and response to wind turbine noise was explored in a cross-sectional study. A study sample of 1,948 people (18 years old or above) were selected among residents living within $2.5 \mathrm{~km}$ of a wind farm with at least two wind turbines of $500 \mathrm{~kW}$ or larger within $500 \mathrm{~m}$ from one another. The selection aimed to get as large a variety of dose levels as possible, which were based on calculated immission levels (A-weighted sound pressure levels) [8]. The characteristics of the area were also taken into account (built-up, rural with main road, rural without main road). Levels of background sound were assessed from community noise maps as LDEN (5 LDEN-interval scale). The selection of the study sample and the calculations of immission levels are described in more detail elsewhere [9].

Response to wind turbines and subjective health status were obtained through a postal questionnaire. The questionnaire was previously developed and used in the Swedish studies $[3,4]$, but modified to suit conditions in the Netherlands and enlarged with the General Health Questionnaire (GHQ) and some questions probing more detail. The questionnaire comprised questions on response to several sources of possible disturbance in the living area, including wind turbines. Response to wind turbine noise was assessed with five different questions which showed high internal consistency (Cronbach's alpha $=0.87$ ). In this paper response to wind turbine noise is based on the outcome of the following question: "Below are a number of items that you may notice or that could annoy you when you spend time outdoors at your dwelling. Could you indicate whether you have noticed these or whether these annoy you?" followed by a list of possible factors of annoyance of which wind turbine noise was one. The question could be answered by a 5 -point verbal rating scale, where $1=$ "do not notice"; 2 = "notice but not annoyed"; 3 = "slightly annoyed"; 4 = "rather annoyed"; and 5 = "very annoyed". Respondents reporting scale point 4 (rather annoyed) or 5 (very annoyed) will in this paper be classified as annoyed.

Attitude towards the noise source was measured both as the general opinion on wind turbines and the impact of wind turbines on the landscape scenery (5-point scale from "very positive" to "very negative"). Noise sensitivity was measured on a 4-point scale from 'not at all sensitive' to 'very sensitive'. The questionnaire also comprised questions measuring self-reported health, well-being and sleep. Stress was measured with 13 items of which 6 were by factor analyses found suitable to form a stress-score 
$($ alpha $=0.84)$. Psychological distress was assessed by the General Health Questionnaire GHQ-12 and a GHQ-score was calculated for each respondent [10]. Sleep quality was assessed with the question "How have you been feeling in the morning during the last months?" (11-point scales; two items; "very rested" to "very sleepy", and "very relaxed" to "very tense") and two questions on the occurrence of sleep disruption by (any) noise. Economical benefits, visibility of wind turbines at the dwelling of the respondent, type of dwelling and description of sound characteristics were also assessed by the questionnaire.

A random sample of the non-respondents $(n=200)$ received a short questionnaire only comprising two key questions where they were asked to rate their annoyance with wind turbine noise outdoors and indoors (scale 0 to 10) so that non-respondent analysis could be carried out.

The respondents were classified into groups of $5 \mathrm{~dB}(\mathrm{~A})$ intervals based on the calculated immission levels at their dwelling. Dose-response relationships are in this paper reported as the proportions of respondents that noticed or were annoyed, respectively, by the noise, in each group of immission levels. Confidence intervals (95\%) were calculated with the Wilson method [11]. Associations between moderating factors and response were tested statistically with binary logistic regression, and adjusted for possible confounders when appropriate. Hosmer and Lemeshow's test (H-L test) was used to test the fit of the model. A p-value $<0.05$ indicates significant differences between the model and the data. Association between annoyance and health scores were tested with multiple linear regression. The adjusted correlation coefficients (Beta) and adjusted $r$-square $\left(\mathrm{R}^{2}\right)$ will be reported here. Spearman's rank correlation test $\left(r_{s}\right)$ was used to test the correlation between two variables. Mann-Whitney U-test $\left(Z_{\mathrm{MWU}}\right)$ or Student's t-test (t) were used to test the difference in distribution of a variable between two samples. All tests were two-sided and outcomes of the test with p-values $<0.05$ were considered statistically significant.

\section{Results}

\subsection{Response rate and non-response analysis}

Of the sent out questionnaires, 725 were satisfactorily returned (Table 1). The response rate was $37 \%$ with a somewhat lower response rate in the groups of sound levels above $35 \mathrm{~dB}(\mathrm{~A})$.

\begin{tabular}{|l|c|c|c|c|c|c|}
\hline $\mathrm{n}=725$ & \multicolumn{5}{|c|}{ Sound pressure levels, $\mathrm{dB}(\mathrm{A})$} & Total \\
\hline & $<30$ & $\begin{array}{c}30- \\
35\end{array}$ & $\begin{array}{c}35- \\
40\end{array}$ & $\begin{array}{c}40- \\
45\end{array}$ & $>45$ & \\
\hline Study sample & 473 & 494 & 502 & 282 & 197 & 1948 \\
\hline $\begin{array}{l}\text { Number of } \\
\text { respondents }\end{array}$ & 185 & 219 & 162 & 94 & 65 & 725 \\
\hline $\begin{array}{l}\text { Response rate, } \\
\%\end{array}$ & 39 & 44 & 32 & 33 & 33 & 37 \\
\hline
\end{tabular}

Table 1. Study sample, number of respondents and response rate at each $5 \mathrm{~dB}(\mathrm{~A})$-interval of sound levels.
The non-respondent survey $(\mathrm{n}=95)$ showed that there was no difference in answers of the two key questions between respondents and non-respondents $(\mathrm{t}=-0.82, \mathrm{p}=0.412 ; \mathrm{t}=$ $0.74, \mathrm{p}=0.458)$.

\subsection{Response to wind turbine sound}

A statistical significant correlation was found between sound pressure levels outside the dwelling of the respondents and the rated perception of and annoyance with wind turbine noise $\left(\mathrm{r}_{\mathrm{s}}=0.501, \mathrm{n}=708, \mathrm{p}<0.001\right)$. The proportion of respondents that noticed the sound from outside their dwelling increased with increasing sound pressure levels (Figure 1). Almost $80 \%$ of the respondents in the group $35-40 \mathrm{~dB}(\mathrm{~A})$ stated that they could hear the sound.

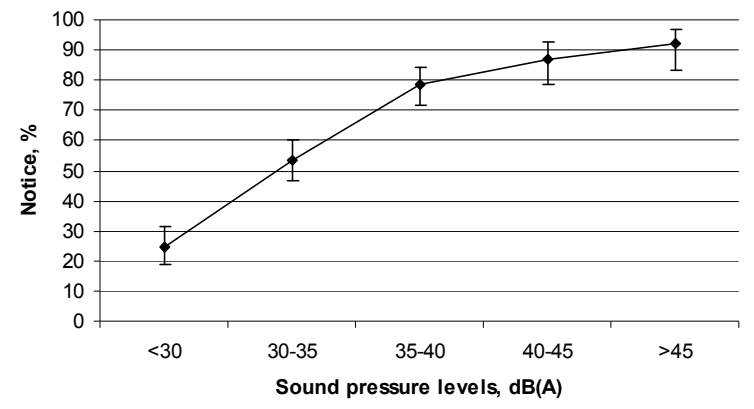

Figure 1. Dose-response relationship between sound pressure levels $(\mathrm{dB}(\mathrm{A}))$ and the proportion of respondents that noticed wind turbine sound outside their dwelling (all

respondents; $n=708$ ) with $95 \%$ confidence intervals.

The number of respondents that were annoyed (rather or very) by sound from wind turbines also increased with increasing sound pressure levels up to 40- $45 \mathrm{~dB}(\mathrm{~A})$ (Figure $2)$. However, the proportion of respondents annoyed decreased at higher levels, though this decrease was not statistically significant.

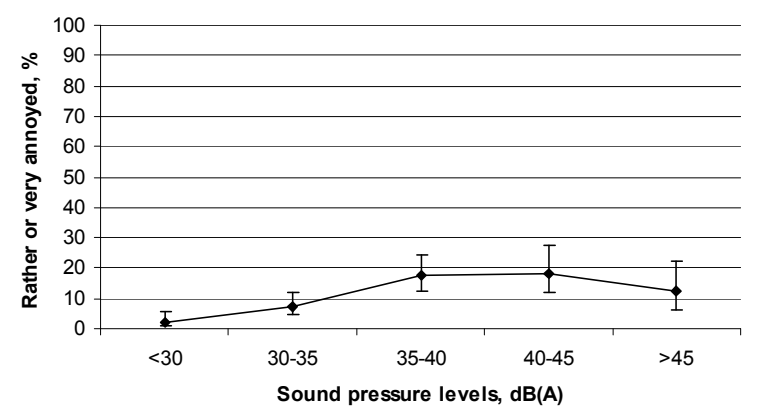

Figure 2. Dose-response relationship between sound pressure levels $(\mathrm{dB}(\mathrm{A}))$ and the proportion of respondents that were rather or very annoyed by wind turbine sound outside their dwelling (all respondents; $\mathrm{n}=708$ ) with 95\% confidence intervals.

Further investigations revealed that many of the respondents that benefited economically from wind turbines belonged to the groups of higher sound pressure levels. In total, 100 respondents benefited economically from the wind turbines, either as owner of wind turbines or share holders, or otherwise, and of these 76 belonged to the groups of sound levels above $40 \mathrm{~dB}(\mathrm{~A})$. Respondents who 
benefited economically from wind turbines were less annoyed by wind turbine sound than other respondents, despite higher exposure levels. Of those who did not benefit, $12 \%$ were rather or very annoyed, and among those who did benefit, 3\%. The difference in distribution was statistically significant $\left(\mathrm{Z}_{\mathrm{MWU}}=-2.55, \mathrm{p}<0.05\right)$. The relationship between sound pressure levels and annoyance with wind turbine noise was therefore explored again, now including only respondents that had stated that they did not benefit economically from the wind turbines $(n=586)$. The proportion of respondents annoyed now increased with increasing sound pressure levels, also at higher levels (Figure 3). The confidence intervals were however large due to a small number of respondents.

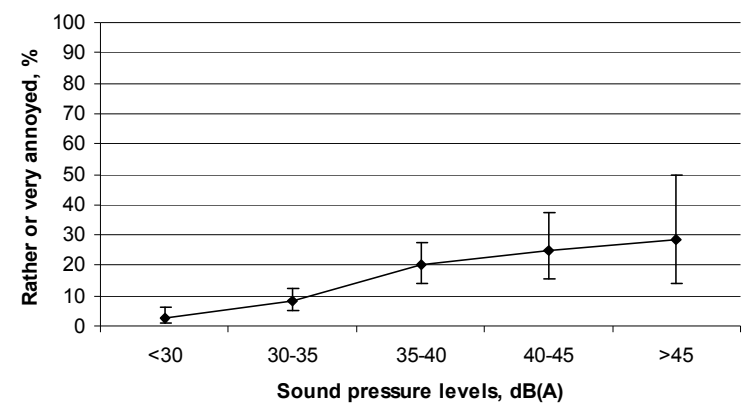

Figure 3. Dose-response relationship between sound pressure levels $(\mathrm{dB}(\mathrm{A}))$ and the proportion of respondents that were rather or very annoyed by wind turbine sound outside their dwelling (respondents who did not benefit economically, $\mathrm{n}=586$ ) with $95 \%$ confidence intervals.

The most common description of wind turbine sound was "swishing/lashing"; 75\% of the respondents who could hear the sound thought that this was a suitable term to characterize the sound (Table 2). "Rustling" was the second most common description, followed by "a low frequency/low pitch sound".

\begin{tabular}{|l|c|c|}
\hline $\begin{array}{l}\text { How would you describe the sound of wind } \\
\text { turbines? }\end{array}$ & $\mathrm{n}$ & \\
\hline Swishing/lashing & 251 & $75 \%$ \\
\hline Rustling & 83 & $25 \%$ \\
\hline A low frequency/low pitch sound & 46 & $14 \%$ \\
\hline Whistling/screeching & 32 & $10 \%$ \\
\hline Thumping/throbbing & 24 & $7 \%$ \\
\hline Resounding & 23 & $7 \%$ \\
\hline Other & 23 & $7 \%$ \\
\hline A pure tone & 11 & $3 \%$ \\
\hline Scratching/squeaking & 10 & $3 \%$ \\
\hline
\end{tabular}

Table 2. Characteristics of the wind turbine sound. Only respondents who could hear wind turbine sound at their dwelling $(n=335)$.

\subsection{Moderating factors}

Several situational factors were found to be associated with annoyance due to wind turbine sound. Respondents who could see at least one wind turbine from their dwelling were more likely to be annoyed by the sound than those who could not see any wind turbines (Table 3). People living in built-up areas were hypothesized to be less annoyed by wind turbine noise than respondents in rural areas and they were therefore chosen as reference group in the analyses of the influence of area type. However, respondents living in rural areas with a main road were less annoyed by the sound than respondents in built-up areas, despite similar levels of background (mostly road traffic) sound. Respondent living in apartments, in comparison to those living in detached houses, were also less likely to be annoyed. The level of background sound had no influence on annoyance due to wind turbine sound.

\begin{tabular}{|l|c|c|}
\hline Not annoyed vs. annoyed & OR & $95 \% \mathrm{Cl}$ \\
\hline Visibility, H-L test $p=0.590$ & & \\
\hline Visibility (no/yes) ${ }^{*}$ & $\mathbf{1 2 . 5 1}$ & $\mathbf{2 . 9 3 7 - 5 3 . 2 7 1}$ \\
\hline & & \\
\hline Urbanization, H-L test $p=0.650$ & & \\
\hline Built-up area* $^{*}$ & 1.0 & \\
\hline Rural area with a main road* & $\mathbf{0 . 2 4}$ & $\mathbf{0 . 1 0 7 - \mathbf { 0 . 5 2 2 }}$ \\
\hline Rural area without main road & 0.67 & $0.356-1.252$ \\
\hline & & \\
\hline Type of dwelling, H-L test $p=0.882$ & & \\
\hline Type of dwelling (house/apartment) & $\mathbf{0 . 4 0}$ & $\mathbf{0 . 1 6 2 - \mathbf { 0 . 9 8 0 }}$ \\
\hline \multicolumn{2}{|c|}{} & \\
\hline $\begin{array}{l}\text { Background sound, } \\
\text { H-L test } p=0.960\end{array}$ & 1.01 & $0.986-1.042$ \\
\hline LDEN (5 LDEN-intervals) & & \\
\hline${ }^{*}$ Adjusted for sound levels, age, gender and economical benefits. \\
\hline
\end{tabular}

Table 3. Relationship between physical factors and being annoyed by sound from wind turbines, adjusted for sound levels, age, gender and economical benefits. The variables were tested one by one with binary logistic regression.

Individual factors were also associated with annoyance. Both a negative attitude towards wind turbines in general and towards the impact of wind turbines on the landscape scenery were associated with annoyance due to wind turbine noise (Table 4). Also, respondents that rated themselves as sensitive to noise were more likely to be annoyed.

\begin{tabular}{|c|c|c|}
\hline Not annoyed vs. annoyed & OR & $95 \% \mathrm{Cl}$ \\
\hline \multicolumn{3}{|l|}{ General attitude, $\mathrm{H}-\mathrm{L}$ test $\mathrm{p}=0.915$} \\
\hline $\begin{array}{l}\text { Attitude to wind turbines in general } \\
\text { (5-point scale) }\end{array}$ & 3.18 & $2.371-4.261$ \\
\hline \multicolumn{3}{|l|}{ Visual attitude, $\mathrm{H}-\mathrm{L}$ test $\mathrm{p}=0.491$} \\
\hline $\begin{array}{l}\text { Attitude to wind turbines' impact on } \\
\text { the landscape (5-point scale) })^{\star}\end{array}$ & 4.10 & $2.841-5.908$ \\
\hline Noise sensitivity, $\mathrm{H}-\mathrm{L}$ test $\mathrm{p}=0.181$ & 1.94 & $1.513-2.489$ \\
\hline \multicolumn{3}{|l|}{ Noise sensitivity (4-point scale) ${ }^{*}$} \\
\hline \multicolumn{3}{|c|}{${ }^{*}$ Adjusted for sound levels, age, gender and economical benefits. } \\
\hline \multicolumn{3}{|c|}{$\begin{array}{l}\text { Table } 4 \text {. Relationship between individual factors and being } \\
\text { annoyed by sound from wind turbines, adjusted for sound } \\
\text { levels, age, gender and economical benefits. The variables } \\
\text { were tested one by one with binary logistic regression. }\end{array}$} \\
\hline
\end{tabular}




\subsection{Health}

No association was found between sound pressure levels and health symptoms, psychological distress or stress. Respondents in the group $>45 \mathrm{~dB}(\mathrm{~A})$ were however more often interrupted in their sleep than respondents in the group $<30 \mathrm{~dB}(\mathrm{~A})(\mathrm{OR}=2.98,95 \%$ CI $1.347-6.597$, adjusted for age, gender, economical benefits and background sound levels).

An increase in annoyance with wind turbine noise was associated with an increased stress score (Beta $=0.12$, $\left.\mathrm{p}<0.01, \mathrm{R}^{2}=0.03\right)$, an increased GHQ-score (Beta $=0.11$, $\mathrm{p}<0.01, \mathrm{R}^{2}=0.03$ ), feeling more sleepy than rested (Beta $=$ $\left.0.08, \mathrm{p}<0.05, \mathrm{R}^{2}=0.22\right)$, and feeling more tense than relaxed in the morning (Beta $=0.09, \mathrm{p}<0.05, \mathrm{R}^{2}=0.22$ ), when adjusted for age, sex, economical benefits and Aweighted sound pressure levels.

\section{Discussion}

In this study it was possible to assess a dose-response relationship between A-weighted sound pressure levels from wind turbines and the possibility to notice the sound at a nearby dwelling. A large proportion of the respondents reported that they noticed the sound already at sound pressure levels $35-40 \mathrm{~dB}(\mathrm{~A})$. The swishing/lapping character of the sound, which was the major descriptor of the sound, is possibly easily perceived and poorly masked by background sound as found in experimental studies [12]. A further explanation may be that wind turbines do not produce less sound at night [9] which is contrary to most other noise sources and therefore obstruct the general need for relatively quiet nights.

A beneficial dependency of the noise source may lead to a lower probability for annoyance. This is indeed the case in this study where the proportion of annoyed persons was small for those with benefits compared to those without. The number of respondents that had economical interests in the wind turbines in this study was large enough so that a statistically significant difference in annoyance with wind turbine noise between respondents benefiting economically and those not benefiting could be shown. The doseresponse relationship between sound pressure levels and annoyance was therefore modeled with a sub-sample of respondents. The proportion of respondents that was rather or very annoyed by sound from wind turbines was approximately the same in the Dutch study as in the previous Swedish studies at most sound levels (Figure 4), except in the group 35-40 $\mathrm{dB}(\mathrm{A})$ where the proportion of Dutch respondents annoyed was somewhat larger. The reason for this is not clear and no statistical differences between respondents in this group and other groups were found that could explain the higher proportion of persons annoyed. Also the unexpected finding that respondents in built-up areas were more likely to be annoyed by the sound than those living in rural areas, is not easily explained. Perhaps people in built-up areas are more sensitive to yet another stimulus, or they may have a different view on environmental values. Though classified as a built-up area, the perception of one's village as a community in a pastoral setting, could have moderated the results.

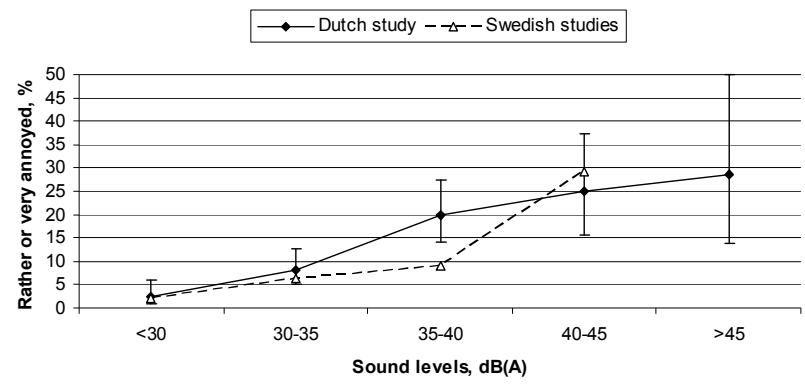

Figure 4. Annoyance with wind turbine sound; comparisons between the Dutch study (only respondents that did not benefit economically, $\mathrm{n}=586)$ and the Swedish studies $(\mathrm{n}=$ 1095). With 95\% CI for the Dutch study.

Respondents who could see at least one wind turbine from their dwelling were more likely to be annoyed by noise than those who could not see any turbines. Stimulation of not only the auditory receptor but also the visual could increase the psycho-physiological reaction.

A negative attitude towards wind turbines was associated with noise annoyance. The study design did not allow conclusions of cause and effect. Meta-analyses of response to community noise have revealed that the direction is dual, i.e. part of the annoyance is due to a negative attitude towards the noise source, and at the same time as part of the negative attitude is due to a negative experience of the sound [13]. There is no reason to believe that it is otherwise in the case of wind turbines.

Several observations call for further analyses. Background sound levels did not have a significant impact on annoyance with wind turbine noise. Possible masking effects, both physical and cognitive, of other sounds such as that of road traffic should be explored. Also the association between noise annoyance at one hand and stress, psychological distress and lowered sleep quality on the other hand needs to be studied further.

The rather large proportion of respondents annoyed by wind turbine sound and the observed risk for sleep interruption at levels above $45 \mathrm{~dB}(\mathrm{~A})$ should be taken into account in the planning of future wind farms.

\section{Acknowledgments}

The study was financed by the European Community through Specific Support Action, contract number 044628. 


\section{References}

[1] S. Krohn, S. Damborg, "On public attitudes towards wind power", Renewable Energy 16, 954-960 (1999)

[2] M. Wolsink, "Wind power implementation: The nature of pulic attitudes: Equity and fairness instead of 'backyard motives",, Renewable and Sustainable Energy Reviews 11, 1188-1207 (2007)

[3] E. Pedersen, K. Persson Waye, "Perception and annoyance due to wind turbine noise: a dose response relationship". J. Acoust. Soc. Am. 116, 3460-3470 (2004)

[4] E. Pedersen, K. Persson Waye, "Wind turbine noise, annoyance and self-reported health and wellbeing in different living environments", Occupational and Environmental Medicine 64, 480 - 486 (2007)

[5] H.M.E. Miedema, C.G.M. Oudshoorn, "Annoyance from transportation noise: relationships with exposure metrics DNL and DENL and their confidence intervals". Environmental Health Perspectives 109, 409-416 (2001)

[6] H.M.E. Miedema, H. Vos, "Noise annoyance from stationary sources: relationships with exposure metric day-evening-night level (DENL) and their confidence intervals", J. Acoust. Soc. Am. 116, 334-343 (2004)

[7] E. Pedersen, P. Larsman, "The impact of visual factors on noise annoyance among people living in the vicinity of wind turbines", Journal of Environmental Psychology. In press.

[8] ISO 9613, Acoustics - attenuation of sound during propagation outdoors. Geneva, Switzerland: ISO (1993)

[9] F. van den Berg, E. Pedersen, R. Bakker, J. Bouma, "Wind farm aural and visual impact in the Netherlands - study group selection and dose calculation", Proceedings of Aucoustics'08, Paris, June 29-July 4 (2008)

[10]R. Sanderman, R. Stewart, "The assessment of psychological distress: Psychometric properties of the General Health Questionnaire (GHQ)", International Journal of Health Sciences 1, 195-202 (1990)

[11]D.G. Altman, D. Machin, T.N. Bryant, M.J. Gardner, Statistics with confidence, 2nd ed. London: BMJ Books (2000)

[12]K. Persson Waye, E. Öhrström, "Psycho-acoustic characters of relevance for annoyance of wind turbine noise", Journal of Sound and Vibration 250, 65-73 (2002)

[13] R.F.S. Job, “Community response to noise: A review of factors influencing the relationship between noise exposure and reaction", J. Acoust. Soc. Am. 83, 9911001 (1988) 